\title{
Transtornos e tumulto, ou uma grande festa da democracia? Contrastes da cobertura jornalística audiovisual da greve geral de 28 de abril no Brasil pelos média tradicional e alternativo
}

\author{
Kamila Bossato Fernandes \\ Universidade do Minho / CECS
}

E-mail: kamila.fernandesdufc.br

\begin{abstract}
Resumo
A cobertura jornalística de manifestações e protestos populares tende a enfatizar aspetos negativos do evento, como demonstram estudos relacionados ao paradigma do protesto. Por sua vez, a fragmentação do ecossistema mediático impulsionada pelas redes sociais digitais tem feito com que outras narrativas sobre um mesmo evento venham à tona e disputem as representações acerca deste tipo de acontecimento. Foi o que aconteceu na greve geral realizada no Brasil no dia 28 de abril de 2017. Neste estudo, proponho uma análise descritiva e comparativa de reportagens audiovisuais produzidas por dois dos principais telejornais brasileiros, o Jornal Naci-

de quatro meios alternativos com difusão pelo Facebook, Jornalistas Livres, Coletivo Nigéria, Marco Zero Conteúdo e Coletivo Catarse. O objetivo é perceber as estratégias discursivas empregadas por cada um deles para construir as narrativas jornalísticas audiovisuais, dando verossimilhança aos relatos ainda que fincados em vieses bem evidentes. Entre as conclusões, nota-se que os meios tradicionais buscaram realçar sua legitimidade a partir das vozes de pessoas comuns, enquanto os meios alternativos fortaleceram fontes contra-oficiais, sobretudo sindicalistas, marcando sua posição institucionalmente ao lado dos interesses dos trabalhadores.
\end{abstract} onal e o Jornal da Record, e produções em vídeo

Palavras-chave: paradigma do protesto; jornalismo tradicional; jornalismo alternativo; objetividade jornalística.

\begin{abstract}
The journalistic coverage of popular demonstrations and protests tends to emphasize negative aspects of the event, as shown by studies related to the protest paradigm. In turn, the fragmentation of the media ecosystem driven by digital networks has made other narratives about the same event come to the surface and dispute the representations about this type of

event. This was what happened in the general strike held in Brazil on April 28, 2017. In this study, I propose a descriptive and comparative analysis of audio-visual reports produced by two of the main Brazilian news TV programs, Jornal Nacional and Jornal da Record, and productions in video of four alternative media with diffusion by Facebook, Jor-
\end{abstract}

Data de submissão: 31/05/2017. Data de aprovação: 30/06/2017.

A Revista Estudos em Comunicação é financiada por Fundos FEDER através do Programa Operacional Factores de Competitividade - COMPETE e por Fundos Nacionais através da FCT - Fundação para a Ciência e a Tecnologia no âmbito do projeto Comunicação, Filosofia e Humanidades (LabCom.IFP) UID/CCI/00661/2013.
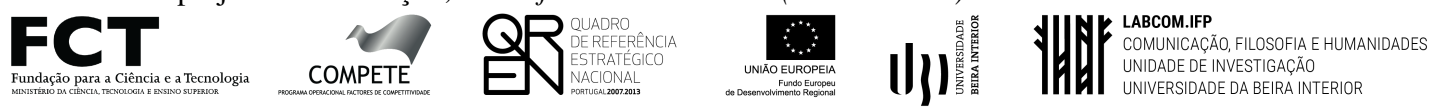
nalistas Livres, Coletivo Nigeria, Marco Zero Conteúdo and Coletivo Catarse. The objective is to understand the discursive strategies employed by each one of them to construct the audio-visual journalistic narratives, giving verisimilitude to the reports, although they are stuck in obvious biases. Among the conclusions, traditional media sought to emphasize their legitimacy from the voices of ordinary people, while alternative means strengthened contraofficial sources, especially trade unionists, by institutionally marking their position alongside workers' interests.

Keywords: protest paradigm; traditional journalism; alternative journalism; journalistic objectivity.

\section{Introdução}

$\mathrm{N}^{\circ}$

DIA 28 de abril de 2017, aconteceram manifestações em várias cidades do Brasil contra mudanças na legislação trabalhista e da Previdência Social propostas pelo governo do presidente Michel Temer. Trabalhadores vinculados a sindicatos e a partidos de esquerda lideraram o movimento, chamado de Greve Geral, por considerarem que as reformas retiram direitos dos trabalhadores. Já o governo e organizações empresariais alegavam que as reformas são imprescindíveis para a retomada do crescimento da economia do país e que não vão prejudicar os mais pobres, mas sim modernizar as leis e favorecer o emprego.

As duas visões deste evento ficaram bem evidentes na cobertura jornalística realizada por diferentes grupos comunicacionais no dia dos protesto: enquanto emissoras de televisão do mainstream enunciavam que a greve era restrita a pequenos grupos de sindicalistas e que gerava transtornos para o restante da população, meios alternativos mostravam o movimento como a maior mobilização trabalhista já realizada no país, uma vitória da cidadania e da democracia em nome da luta pela manutenção de direitos. Mais do que o viés dado por cada uma das coberturas, porém, neste trabalho proponho analisar as estratégias discursivas utilizadas por diferentes media que utilizam a linguagem audiovisual para estabelecer o discurso jornalístico durante a cobertura deste dia de manifestações.

Para tanto, inicialmente irei traçar uma discussão sobre a questão da verdade no jornalismo, e em seguida apresentarei os preceitos que demarcam estudos fincados no paradigma do protesto. Para, enfim, apresentar o percurso metodológico, baseado na análise crítica do discurso multimodal (Machin \& Mayr, 2012). Serão analisados conteúdos em vídeo produzidos por dois telejornais, o Jornal Nacional, da TV Globo, e o Jornal da Record, da TV Record, e por quatro grupos de jornalismo alternativo, Jornalistas Livres, Coletivo Nigéria, Coletivo Catarse e Marco Zero Conteúdo.

Entre as conclusões, nota-se que os meios tradicionais buscam legitimidade pela voz de pessoas comuns, inseridas em grande quantidade ao longo da sua cobertura para representar a opinião pública, validando sua posição negativa em relação aos protestos. Enquanto os alternativos se apoiam no discurso das lideranças sindicais para enfatizar o conflito de interesses que se materializa nas manifestações, sendo os interesses do governo atrelados aos do mercado, e os interesses dos trabalhadores, aos dos sindicalistas. 


\section{A questão da verdade no jornalismo}

A prática jornalística tem estreita ligação com a difusão da verdade. Verdade no sentido ontológico, ou da experiência, relacionada diretamente com o que se considera o real e se efetiva pela ideia de fato (Sponholz, 2003, p. 56). Assim, mais do que trazer relatos afirmativos, é necessário demonstrar que os fatos aconteceram e não são obras de ficção. Contudo, no processo de transformar o fato em representação, mais do que chegar a um valor de verdade, o discurso jornalístico produz efeitos de verdade, aceitos na dimensão epistêmica, da crença (Charaudeau, 2006). Assim, o jornalismo não traz uma verdade, mas apresenta um discurso que cremos que é verdadeiro.

O compromisso com a verdade foi enfatizado no processo de profissionalização do jornalismo como uma prática socialmente legitimada a partir de certos padrões de atuação e de comportamento profissional. Como relata Schudson (2001), a partir do conjunto de valores e normas estabelecidos na ideia de objetividade jornalística, difundidos sobretudo após a Primeira Guerra Mundial, no início do século XX, definiu-se não apenas o que é, mas também o que não é aceitável na prática jornalística. O que aconteceu mais para normalizar o campo (Schudson, 2001; Tuchman, 1972), constituindo assim o que se tornou a ideologia do jornalismo (Deuze, 2005). Entre os valores e normas que integram a objetividade jornalística estão a separação entre informação e opinião, a busca pelo equilíbrio e a imparcialidade, o que reforça o caráter descritivo do relato jornalístico.

Contudo, como constata a análise crítica do discurso (ACD), não há discurso neutro, isento de ideologia, ou plenamente objetivo. "Comunicar, informar, tudo é escolha" (Charaudeau, 2006, p. 39). E por causa da impossibilidade de aplicar este valor em sua integralidade, ainda que mantenha-se como a prática hegemônica (Carpentier \& Trioen, 2010), a objetividade jornalística tem sido criticada por pesquisadores de diferentes orientações teórico-metodológicas (Hall, 1978; Moretzsohn, 2002; van Dijk, 2015). Entre as críticos, Boykoff e Boykoff (2004) chegaram a demonstrar que a aplicação acrítica dos valores da objetividade, tais como o equilíbrio (balance), acaba por distorcer acontecimentos. Estudos que buscaram identificar o viés de coberturas jornalísticas, a partir do paradigma do framing (Entman, 2004; Hopke, 2012; McLeod \& Detenber, 1999), também acabaram por colocar em xeque qualquer possibilidade de chegar a uma verdade pura, ao identificar versões, ou vieses, presentes nos textos jornalísticos.

A crítica à objetividade jornalística também faz parte do referencial de atuação de certos grupos de jornalismo alternativo (Atton, 2011; Atton \& Hamilton, 2008). Em termos gerais, podemos considerar, a partir da visão de Forde (2011, p. 167), que o jornalismo alternativo é marcado pela sensação de responsabilidade social, apresenta entre seus compromissos principais incentivar a participação cívica da sociedade, descobrir histórias não contadas e abrir espaço para representar os que não têm acesso aos meios tradicionais. Muitas vezes, tal prática mantém vínculos com movimentos sociais (Rodriguez, 2001) e sua produção está associada à da comunicação para a transformação social (Rodriguez, Ferron, \& Shamas, 2014).

Apesar de rejeitar muitas vezes a objetividade, quando falamos de jornalismo alternativo, nos referimos a uma prática associada aos mesmos sentidos de verdade assumidos pelo jornalismo tradicional, atrelados à verificabilidade do fato e narrados a partir de certas estratégias discursivas que garantem verossimilhança aos relatos. A diferença mais nítida é que os alternativos em geral 
assumem um lado e defendem claramente certas posições, incorporando um valor adicional, o da transparência. Assim, enquanto meios de comunicação tradicionais em geral propõem realizar coberturas imparciais, os alternativos denunciam tal impossibilidade e costumam demonstrar simpatia ou apoio às manifestações, ainda que também possam recair em diversas recorrências verificadas pelo paradigma do protesto (Reul, Paulussen, Raeijmaekers, van der Steen, \& Maeseele, 2016), como veremos a seguir.

\section{Paradigma do protesto}

A forma como os jornais registram manifestações sociais levou pesquisadores a investigarem tendências que marcam este tipo de cobertura. O que originou a proposta do chamado paradigma do protesto. Inicialmente proposto por Chan e Lee (1984), o paradigma identificou que, em geral, a cobertura segue padrões e rotinas que colocam as manifestações em desvantagem.

Ao analisar a cobertura de protestos antiguerra pela imprensa norte-americana, Dardis (2006, p. 122) identificou 14 categorias que em geral são acionadas neste tipo de cobertura e que podem contribuir para identificar em que medida os jornais aderiram mais ou menos ao paradigma do protesto: 1) a ênfase na completa falta de lei, verificada quando há referências a situações de violência, vandalismo e ao bloqueio de vias públicas, por exemplo; 2) o destaque aos confrontos dos manifestantes com a polícia; 3 ) show de horrores, acionado quando são destacadas características físicas dos manifestantes, como tatuagens, piercings, cabelos longos, roupas estranhas; 4) a infantilização dos manifestantes, percebida quando enfatiza-se danças e jogos; 5) carnavalização do protesto; 6) dados estatísticos; 7) generalizações, feitas sem a referência a dados; 8) a visão de testemunhas; 9) uso de fontes oficiais, em detrimento da voz dos manifestantes; 10) o protesto como uma traição; 11) protesto como anarquia; 12) protesto como antimilitares; 13) a inclusão de contramanifestantes; 14) comparações históricas. Nem todos as características são empregadas no sentido negativo, de desqualificar os protestos, mas em geral há certos padrões mais persistentes, como o autor pontua, como as referências à falta de respeito às leis como recurso empregado pelos jornais de modo recorrente e que marginaliza as manifestações.

O que não significa que todas as coberturas de protestos empreguem tais padrões e sejam negativas em relação às manifestações, como pondera o próprio Dardis (2006, p. 122). Lee (2014) considera que, com as mudanças no ambiente mediático e nas dinâmicas internas do campo dos movimentos sociais, hoje é mais adequado pensar no paradigma como uma variável cuja aplicação deve ser feita para verificar níveis de cobertura, que variam de acordo com o local, as relações políticas do meio de comunicação com o poder e com o tipo de protesto (Lee, 2014, p. 2.726).

Tendo como foco manifestações que aconteceram em 2013 em China, Índia e Brasil, Shahin, Zheng, Sturm e Fadnis (2016), a partir do que propuseram Hallin e Mancini (2004), aplicaram quatro dimensões fundamentais para melhor compreender a adesão ou não ao paradigma do protesto por cada um desses países: o desenvolvimento histórico dos meios de comunicação de massa; vínculos entre os meios jornalísticos e interesses políticos organizados; o nível de profissionalismo jornalístico; e o grau de intervenção do estado. Entre as conclusões do trabalho está que, mais do que convicções ideológicas dos meios de comunicação, o que influencia na adesão ao paradigma do protesto é o alinhamento com o governo (Shahin et al., 2016, p. 158). No caso brasileiro, por 
exemplo, verificou-se que, à medida que os protestos de 2013 passaram a ter como alvo o governo da presidente Dilma Rousseff, do Partido dos Trabalhadores (de centro-esquerda), os jornais passaram a ser mais simpáticos aos manifestantes, o que demonstra que eles não eram "naturalmente" contrários aos protestos.

A marginalização dos protestos, através do uso de estratégias de deslegitimação na cobertura, não atinge apenas manifestações ligadas a grupos políticos de esquerda, anti-status quo (Boyle, McLeod, \& Armstrong, 2012), mas de direita também, como mostraram Weaver e Scacco (2013) ao analisar a cobertura de protestos ligados ao Tea Party, nos Estados Unidos. Por outro lado, há pesquisas que indicam que, entre os meios de comunicação alternativos, existe uma tendência a favorecer os protestos, ainda que, em grande parte, seja dada grande atenção aos eventos violentos relacionados ao protesto do que propriamente às demandas dos manifestantes (Reul et al., 2016). Além disso, ao circular nas redes sociais, coberturas dos protestos com teor mais positivo em relação as protestos parecem ter maior aprovação do público do que coberturas negativas (Harlow, Salaverría, Kilgo, \& García-Perdomo, 2017).

Para além do paradigma do protesto, Cammaerts (2012) propõe pensar na articulação entre as manifestações sociais e a comunicação, a partir do que chamou de estrutura de oportunidade de mediação. Ele sugere que é necessário pensar no processo comunicacional como um todo, não só a partir da ação dos media, mas também dos próprios ativistas, que, segundo o autor, passaram a se dar conta da relevância da comunicação e a querer maior visibilidade mediática, como instrumento útil para alcançar certos objetivos das manifestações. Com esse intuito, os manifestantes acabam por adaptar certas ações à lógica mediática, inclusive do mainstream.

\section{Metodologia de análise}

A maioria dos estudos que aplicam o paradigma do protesto o fazem pela análise do framing, seja ela uma análise visual ou não (Harlow, 2017). Entre alguns exemplos estão Gitlin (1980), McLeod e Detenber (1999) e Harlow, Salaverría, Kilgo e Garcia-Perdomo (2017). Neste trabalho, entretanto, não seguirei tal tendência. A partir de uma análise exploratória inicial, já parto do pressuposto de que a cobertura feita pelos dois telejornais escolhidos, de meios de comunicação tradicionais, utiliza estratégias que deslegitimam os protestos em questão, ao mesmo tempo em que os grupos alternativos demonstram apoiar as manifestações. Nesta análise, interessa identificar as estratégias discursivas utilizadas para estabelecer estes frames com o intuito de estabelecer narrativas relacionadas a um status de verdade, e para tanto aplicar-se-ão as ferramentas da análise multimodal da semiótica social. Afinal são duas versões absolutamente contraditórias da mesma história: o que é mostrado em um lado, e não é no outro? Como essas questões são mostradas? E por que isso acontece (que aspetos ideológicos podem ser extraídos dessas versões)?

A análise multimodal (Kress \& van Leeuwen, 2001; O'Halloran, 2011) apresenta um conjunto de procedimentos para a análise de produções mediáticas em geral, mas especialmente quando se trata de conteúdos que mesclam diferentes modos de comunicação, tais como texto, áudio e imagens, por apresentar caminhos que levam à interpretação dos sentidos produzidos a partir da combinação desses diferentes elementos (Machin \& Mayr, 2012). Associada à análise crítica do discurso, contribui para preencher a lacuna dos estudos linguísticos de perceber a ligação entre 
linguagem, poder e ideologia (Machin \& Mayr, 2012, p. 3), ao desnaturalizar a forma como os discursos são construídos, contrapondo-o às escolhas possíveis que giram no seu entorno.

A análise tomará por base o caminho esmiuçado por Machin e Mayr (2012), a partir dos preceitos da gramática funcional de Halliday (1985), em que são trabalhados os elementos lexicais (o que está dito e o que não está, mas poderia estar dito), sobre as diferentes linguagens presentes no conteúdo, de modo a ser possível identificar como são significadas as ideias, os valores, as identidades e as sequências de atividades ali representadas, mesmo quando elas não são claramente identificadas (Machin \& Mayr, 2012, p. 11). O que evidentemente não se restringe à estrutura física de palavras, imagens e sons, mas às formas como tais representações são apropriadas socialmente e aplicadas para alcançar determinados fins, afinal, como explica Halliday (1985), as palavras (e os elementos não linguísticos) não significam apenas o que está nelas, mas significam a partir do que se estabelece na rede de sentidos em que estão contidas. O que torna fundamental a contextualização da produção e do evento social relatado pelos media.

Para tanto, será feita inicialmente uma rápida contextualização do protesto e do posicionamento de cada grupo de comunicação, seguida da descrição de cada cobertura, para, em seguida, ser feita uma análise a partir de: 1) fontes usadas para estabelecer os relatos; 2) termos e imagens usadas para se referir à manifestação; 3 ) termos e imagens usadas para se referir aos manifestantes; 4) referências usadas para tratar os motivos do protesto; e 5) referências usadas para explicitar a opinião pública sobre o protesto.

\section{A greve geral de 28 de abril, emissoras de televisão e grupos alternativos}

A manifestação denominada greve geral foi organizada em todo o Brasil para o dia 28 de abril de 2017, em protesto contra as reformas trabalhista e da Previdência. Propostas que entraram na agenda pública após o impeachment da presidente Dilma Rousseff, do Partido dos Trabalhadores, em 2016, e que tem o apoio de organizações empresariais.

Em termos comunicacionais, a TV aberta no Brasil segue líder de audiência entre as mais diferentes camadas da população e as duas emissoras escolhidas são as que concentram a maior fatia de público. A TV Globo faz parte do maior grupo de comunicação do país, sendo o Jornal Nacional o telejornal mais assistido entre os brasileiros. A emissora foi criada em 1965 pelo jornalista Roberto Marinho (a família Marinho segue sendo proprietária), e sua história é atrelada ao apoio à ditadura militar (1964-1985) e à oposição aos governos de Luiz Inácio Lula da Silva (2003-2010) e de Dilma (2011-2016). Justamente por esses posicionamentos, e por situações de manipulação jornalística vividas no passado, a emissora costuma ser duramente criticada por movimentos sindicais e sociais pela cobertura que faz de posicionamentos contrários a propostas neoliberais. Já a TV Record existe desde 1953, mas no início dos anos 1990 passou a pertencer a Edir Macedo, líder do grupo religioso Igreja Universal do Reino de Deus. Tal grupo tem fortes interesses políticos, com parlamentares e governantes eleitos em todo o país, e age em defesa de uma agenda conservadora, anti-aborto, anti-casamento entre homossexuais, e em favor de interesses empresariais. Assim como a Globo, também atuou contra o governo Dilma.

Já os grupos de média alternativa elencados para análise, Jornalistas Livres, Coletivo Nigéria, Marco Zero Conteúdo e Coletivo Catarse, surgiram entre 2011 e 2015 (com exceção do Coletivo 
Catarse, que é de 2004), com o advento das redes sociais como fenômeno comunicacional no Brasil. Segundo a agência eMarketer ${ }^{1}$, até o final de 2017 deverão existir 92,5 milhões de usuários do Facebook no Brasil, alcançando-se cerca de $45 \%$ da população e $75 \%$ dos usuários de internet no país. A atuação dos grupos alternativos ganhou relevo a partir das manifestações iniciadas em junho de 2013 no país, e que se repetiram em 2014. O Jornalistas Livres foi lançado em 2015 e tem uma ação voltada para dar visibilidade a movimentos sociais, organizados ou não, com uma pauta política progressista. Foi frontalmente contrário ao impeachment de Dilma, o qual considera ter sido um golpe. O Coletivo Nigéria foi lançado em 2011 em Fortaleza, no Nordeste brasileiro, como uma produtora de conteúdo para movimentos sociais e organizações não governamentais (ONGs). Em 2013, com os protestos, começou a produção jornalística eventual, que resultou em documentários. O Marco Zero Conteúdo também foi criado no Nordeste, na cidade do Recife, em 2014, e dá ênfase à cobertura local de fatos de interesse dos movimentos sociais e de grupos políticos de esquerda, com críticas às políticas neoliberais. Também condenou o impeachment de Dilma. Já o Coletivo Catarse é sediado em Porto Alegre, no sul do Brasil, e desde sua fundação desenvolve produções comunicacionais em parceria com movimentos sociais, ONGs e entidades públicas para divulgar ações culturais, em prol dos direitos humanos.

\section{Resumo das coberturas}

\section{a) Jornal Nacional}

Apresentado pelos jornalistas William Bonner e Renata Vasconcellos, o telejornal dedicou 21 minutos e 43 segundos, um pouco mais da metade da sua duração total (de 40 minutos), às manifestações ${ }^{2}$. O tempo foi dividido entre oito matérias e duas notas de estúdio, lidas pelos apresentadores. Seis matérias deram destaque à interrupção dos transportes públicos por todo o país. A baixa adesão de manifestantes aos protestos e a violência presenciada em alguns locais também foram referenciados. A cobertura foi encerrada com um vídeo em que a emissora justifica a própria cobertura, demonstrando o quanto acompanhou de perto as mobilizações, com imagens de todo o país.

\section{b) Jornal da Record}

O telejornal, apresentado por Celso Freitas e Adriana Araújo, destinou 19 minutos ao tema, quase um terço do seu tempo total (de 50 minutos) ${ }^{3}$. Foram sete reportagens, uma entrada de repórter em direto e uma nota de estúdio. A ênfase dada nas três primeiras matérias foi na violência e no vandalismo das manifestações, para, em seguida, ser tratada a falta de transporte público nas

1. Um resumo do estudo pode ser visto no link www.emarketer.com/Article/eMarketer-Updates-Worldwide-SocialNetwork-User-Figures/1016178. Acesso em: 28 set. 2017.

2. O programa completo pode ser visto em http://g1.globo.com/jornal-nacional/edicoes/2017/04/28.html\#!v/ 5834689. Acesso em 18/10/2017.

3. O programa completo pode ser visto em http://noticias.r7.com/jornal-da-record/videos/assista-a-integra-dojornal-da-record-desta-sexta-feira-28-29042017. Acesso em 18/10/2017. 
principais capitais do país. O lado do governo mereceu uma matéria específica, mostrando o quanto a Presidência da República considerou o protesto irrelevante.

\section{c) Alternativos}

O grupo Jornalistas Livres acompanhou as manifestações durante todo o dia, especialmente a partir da cidade de São Paulo, onde tem sede, mas também dando espaço para outras cidades, com emissões em direto, entrevistas em estúdio e galerias de fotos. Entre as emissões em direto, foram mostrados atos do protesto. Também foram feitas entrevistas com sindicalistas, políticos declaradamente contrários à reforma trabalhista e outros apoiadores do movimento grevista. Para este trabalho, foram considerados quatro vídeos do grupo.

Com sede em Fortaleza, o Coletivo Nigéria fez uma cobertura pontual, com um vídeo em que mostrava o bloqueio de uma avenida por manifestantes. A edição acompanha a tática usada pelos ativistas até a chegada de seguranças, que reagiram com violência para dispersá-los.

O Marco Zero Conteúdo priorizou a mobilização que aconteceu no Recife, mostrando a concentração de pessoas em apoio à greve geral. Atos no interior do Estado de Pernambuco também foram mostrados, bem como a adesão da população à greve, com o esvaziamento das ruas e o comércio fechado. A cobertura foi feita com galerias de fotos e vídeos. Para este trabalho, serão analisados dois vídeos do grupo.

O Coletivo Catarse fez a cobertura com a publicação de um vídeo e uma galeria de fotos sobre o protesto que aconteceu em Porto Alegre, com destaque à fala de sindicalistas e de apoiadores do movimento grevista.

\section{Análise}

\section{1) Fontes usadas para estabelecer os relatos}

No Jornal Nacional, a maioria das fontes utilizadas nas matérias não era oficial. Foram ouvidas 10 pessoas comuns, e muitas delas (7) não receberam sequer identificação. Entre elas, duas tiveram posição favorável aos protestos. As demais foram inseridas no sentido negativo, ao reclamar dos efeitos das manifestações, como a falta de transporte público para chegar ao trabalho e a falta de funcionamento do comércio. Sindicalistas (4) e manifestantes (2) também foram ouvidos nas matérias, ainda que, logo após as suas falas, a narrativa recorrentemente trouxesse aspectos negativos dos protestos, como momentos de confronto e de vandalismo. Foi o que aconteceu, por exemplo, logo após a fala de uma manifestante fantasiada de palhaça, identificada como professora, que criticava a reforma da Previdência. Logo após a fala dela, volta a narração do repórter dizendo que a passeata terminou em confronto, com imagens de policiais espancando um homem, seguida de outra em que um grupo de manifestantes aparecia quebrando portas de vidro. Foi dado espaço ainda ao governo e à fala de um grupo empresarial. Ambos minimizaram os protestos, alegando que foram insignificantes e que não interromperam a produção econômica. A polícia não falou.

Assim como fez o Jornal Nacional, o Jornal da Record também priorizou falas de pessoas comuns, mas a maioria delas identificadas e todas com falas contrárias aos efeitos da greve. Foram 
treze pessoas identificadas por nome, sobrenome e atividade profissional, com histórias sempre associadas a algum tipo de prejuízo causado pelo dia de protestos. Os prejuízos alegados eram de duas naturezas: ou financeiros, ou à saúde. A versão do mercado é enfatizada por um corretor financeiro: "não vamos aderir a este tipo de movimento porque o mercado não para". Não foram inseridas falas de sindicalistas e a única pessoa que apareceu falando em defesa das manifestações foi uma mulher não identificada, que tinha os olhos vermelhos por causa de um ataque da polícia com bomba de efeito moral. Além das pessoas comuns, ainda foram incluídas as falas de um ministro, do presidente Temer e de um advogado, que acusou os sindicatos de não prestar contas aos seus sindicalizados nem respeitar decisões judiciais, atuando, assim, de forma ilegal. O mesmo advogado considera ainda que o direito de greve é inferior ao direito de ir e vir de quem não quer participar dos protestos, ampliando a ilegalidade do movimento.

Entre os grupos alternativos, o Jornalistas Livres priorizou falas de sindicalistas. Desde o início dos protestos, na madrugada do dia 28, o grupo começou a colocar no ar emissões ao vivo com entrevistas com lideranças sindicais que falavam sobre a paralisação. Na primeira dessas emissões ${ }^{4}$, trabalhadores do Metrô de São Paulo já davam conta de que toda a categoria havia aderido à greve, que já se configurava como a maior da história do país, e que a população em geral apoiava o movimento grevista. Além dos sindicalistas, o grupo também deu destaque à opinião de seus jornalistas, como o que aconteceu durante uma passeata, na qual a jornalista considerou que o movimento estava "imenso", "o cenário da manifestação é lindo", uma "puta manifestação maravilhosa", e que "o governo tá levando um susto com a força da luta, a força do povo brasileiro", ainda que nenhuma fonte do governo tenha sido ouvida.

O Coletivo Nigéria optou por utilizar uma linguagem mais próxima do chamado cinema direto, ou cinema verdade, sem uso de narração em off e só a câmera na mão, mas com imagem em alta resolução, e sem inserção de trilha sonora. Foram inseridas duas entrevistas no vídeo de 5'30" 5 , mas sem qualquer identificação das fontes. Pressupõe-se que um dos entrevistados seria líder do Movimento dos Trabalhadores Sem Teto (MTST) em Fortaleza, e o outro uma mulher que integra um movimento jovem. Em sua fala, o líder dos sem-teto anuncia o início da greve geral no país com aquele ato que bloqueava a saída veículos de uma empresa de transporte público.

O Marco Zero Conteúdo não faz qualquer entrevista nos vídeos que colocou no ar. Apenas expõe a voz dos manifestantes entoando alegremente gritos de guerra de "fora Temer". Já o Coletivo Catarse opta, a exemplo do que fez o Nigéria, por montar uma narrativa com baixa interferência de edição, sem narração em off do repórter, mas em que usou falas de entrevistados para guiar o seu posicionamento. Foram ouvidos uma jornalista que atua na TV pública do Rio Grande do Sul e um militante de movimento social, ambos identificados. As falas foram em apoio à greve e argumentavam contra as propostas do governo. A jornalista, além disso, apresentou uma reflexão sobre o papel da comunicação na cobertura das reformas trabalhista e da Previdência, com críticas à atuação das emissoras de TV comerciais. "Cadê o contraponto?", questiona a jornalista. O que as posiciona contra o interesse público, e lança os meios alternativos como necessários para defender a população.

4. Vídeo disponível em www.facebook.com/jornalistaslivres/videos/520783821378833/. Acesso em 23/10/2017.

5. O vídeo está disponível em www.facebook.com/coletivoNigeria/videos/1565625940178205/. Acesso em 25/10/2017. 


\section{2) Termos e imagens usadas para se referir à manifestação}

O Jornal Nacional se referiu ao dia de protestos como "dia de manifestações contra as reformas da Previdência e trabalhista", utilizando apenas uma vez o termo "greve geral". Desde a primeira matéria, o telejornal atribuiu o movimento às centrais sindicais, não citando outros movimentos sociais ou a participação de cidadãos sem vínculo institucional. Para mostrar os protestos, muitas imagens eram aéreas, distantes, o que impedia identificar indivíduos e ver rostos dos manifestantes Uma das formas usadas para dimensionar os protestos foi pelo uso de números, indicando a quantidade de pessoas que participaram de certas ações, mas especialmente quando eram poucos manifestantes. Por mais de uma vez, os repórteres se referiram às manifestações como "pequenas" passeatas. De modo cíclico, a reportagem mostrou protestos que começavam pacíficos, mas que acabavam em confrontos com a polícia e em atos de vandalismo, como pichações de paredes, cabines telefônicas quebradas e latas de lixo incendiadas. Situações em que os protestos passavam a ser chamados de "tumulto", "baderna" e "confrontos". A polícia aparecia como tendo de "reagir" e o excesso de força da ação policial não foi questionado: foi situado na mesma proporção que os ataques dos manifestantes, ainda que os policiais estivessem fortemente armados.

O principal mote usado como referência às manifestações pelo telejornal foi a interrupção do transporte público. Assim, mais do que atos de protesto, foram mostrados pátios de empresas de ônibus cheios de veículos parados, linhas de trem e metro vazias e pessoas à espera do transporte para tentar ir trabalhar. Também houve ênfase no trânsito parado, mesmo em cidades onde é rotina o excesso de trânsito. Não foi apresentado qualquer parâmetro comparativo em relação ao trânsito em dias normais.

No Jornal da Record, a manifestação foi situada em oposição à legalidade, sendo associada aos termos "tumultos", "depredações" e a ações que prejudicaram diretamente trabalhadores que não puderam se locomover durante o dia. O dia foi de "agitação", segundo a reportagem, com "clima de guerra". O termo greve foi usado apenas em uma reportagem da cobertura, que buscava demonstrar como o direito de ir e vir das pessoas foi afetado pelo que se conclamou como o direito de greve. $\mathrm{O}$ dia de manifestações foi também associado ao medo e ao risco de sofrer algum tipo de violência, o que foi ilustrado com imagens da polícia disparando balas de borracha e bombas de efeito moral contra os manifestantes, barricadas pegando fogo e uma passeata atribuída aos chamados "black blocs", grupo que passou a ser conhecido no Brasil em 2013 pelo uso de táticas radicais, como quebrar vitrines de lojas e agências bancárias e incendiar veículos.

Pelo olhar dos Jornalistas Livres, a manifestação foi um ato de grande proporção, com imensa adesão social, plural e justo. A grandiosidade se manteve mesmo nas situações de embate com a polícia, como na emissão em direto feita do Rio de Janeiro ${ }^{6}$. Com uma narração em off, a emissão foi feita por um telemóvel na vertical, e tinha as imagens em baixa resolução, muitas vezes borradas. Essa emissão ficou no ar por 46 minutos. A repórter relata que o protesto havia se esvaziado por causa da violência policial, que não reagiu, e sim atacou os manifestantes.

Também no sentido inverso ao que fizeram as emissoras de TV, o Coletivo Nigéria usou as imagens dos bloqueios em via pública com pneus incinerados não para ilustrar o caos ou o desres-

6. Vídeo disponível em www.facebook.com/jornalistaslivres/videos/521429137980968/. Acesso em 24/10/2017. 
peito ao direito de ir e vir, mas como parte da mobilização e da luta dos trabalhadores. O protesto também foi simbolizado como momento de festa dos trabalhadores, com os manifestantes pulando e cantando em frente ao fogo, bem como uma situação de enfrentamento. O que foi evidenciado no momento em que, para impedir a saída dos ônibus, os manifestantes, organizados, se sentaram no chão, em frente aos veículos, em uma resistência pacífica.

Marco Zero Conteúdo e Coletivo Catarse ilustram o protesto, com imagens e som, como uma grande festa. Em um dos vídeos do Marco Zero $^{7}$, feito no Recife, manifestantes aparecem dançando ao som do ritmo de frevo e cantando, aos pulos, "fora Temer". Não há qualquer narração ou contextualização do evento. Em outro vídeo ${ }^{8}$, a manifestação aparece como um evento popular, uma feira, com pessoas conversando, barracas de comida, música, tudo misturado em uma praça pública repleta de pessoas. Imagens que, descontextualizadas, se aproximam de outros eventos que levam à ocupação de vias públicas na cidade, como o Carnaval e o Réveillon. Já o Catarse ${ }^{9}$, sediado em Porto Alegre, introduz informações sobre o dia de protestos, tanto a partir da fala de entrevistados, como ao focar em faixas e cartazes que condenam as reformas da Previdência e da legislação trabalhista, mas em geral mostrando cenas da manifestação repletos de alegria, com os manifestantes sorrindo, fantasiados, segurando faixas e cartazes e cantando "Eu tou na luta, na resistência, contra a reforma da Previdência".

\section{3) Termos e imagens usadas para se referir aos manifestantes}

O Jornal Nacional mostrou os manifestantes de dois modos: como sindicalistas, referidos no uso do termo coletivo "centrais sindicais", e como "grupos mascarados". Os sindicalistas eram apresentados como grupos organizados, que lideraram as pequenas passeatas, enquanto os mascarados eram responsáveis pelos atos de vandalismo e pelos "confrontos" com a polícia. Manifestantes feridos chegaram a ser mostrados, mas não foram chamados de manifestantes, e sim de estudantes e jovens, sem a identificação clara de quem seriam os autores de alguns desses ferimentos.

O Jornal da Record também buscou associar as pessoas que participaram do dia de paralisação às centrais sindicais, mas preferiu referir-se a elas como "grupos de manifestantes ligados a centrais sindicais", contrapondo-os diretamente aos "trabalhadores", prejudicados pela iniciativa. Não houve qualquer tentativa de distinguir os vândalos ou mascarados dos demais manifestantes. Os "manifestantes" foram associados diretamente a atos de tumulto e, em dois momentos, foram referenciados por nomes de organizações específicos, primeiro como "grupo que se autodenomina anarcopunk", e depois como "black blocs", ainda que as imagens mostrassem uma multidão participando do protesto e bandeiras de sindicatos ao fundo. Em uma fala atribuída à polícia, houve uma referência a "vândalos infiltrados" nas manifestações.

Os manifestantes foram representados pelo grupo Jornalistas Livres a partir de imagens feitas em meio à manifestação, em que era possível ver diferentes rostos, ouvir palavras de ordem e identificar comportamentos. Em geral, o grupo priorizou mostrar os manifestantes em atos de

7. Vídeo disponível em www.facebook.com/mzconteudo/videos/1892097187715389/. Acesso em 25/10/2017.

8. Vídeo disponível em www.facebook.com/mzconteudo/videos/1892020761056365/. Acesso em 25/10/2017.

9. Vídeo disponível em www.youtube.com/watch?v=D-OFhFs19JQ\&feature=youtu.be. Acesso em 25/10/2017. 
civismo pacífico, segurando faixas, bandeiras, entoando gritos de guerra, a partir da liderança de sindicalistas, ativistas de movimentos sociais e políticos de esquerda, que lançavam críticas às "reformas de Temer". Mesmo em situações de tensão com a polícia, ao contrário do que fizeram as emissoras de TV, o Jornalistas Livres não se referiu a mascarados ou vândalos, mas a "grupos de ação direta" e a "grupo que deixa recados nos muros", que agiam em reação à violência sofrida.

Com a câmara sempre muito próxima dos manifestantes, o Coletivo Nigéria enfatizou a organização dos envolvidos e a resistência dos manifestantes, mesmo em situação de risco. Representação que ganha corpo, na edição, com o grito de guerra dos manifestantes "Aqui está o povo sem medo, sem medo de lutar" repetidas vezes. Já o Marco Zero Conteúdo e o Coletivo Catarse apresentaram os manifestantes como pessoas alegres, cidadãs, e não sindicalistas radicais. Alegria visível em rostos sorridentes, em conversas tranquilas e em cantorias de palavras de ordem.

\section{4) Referências usadas para tratar os motivos do protesto}

O Jornal Nacional buscou associar o dia de protestos à insatisfação das centrais sindicais, e não dos trabalhadores em geral, com as propostas do governo Temer para as reformas trabalhista $\mathrm{e}$ da Previdência, e acabou por dedicar um infográfico para explicar certos aspetos de cada reforma, como em uma lista, inserindo pontualmente argumentos dos sindicatos contra as medidas, bem como a defesa do governo, que sempre aparece como a palavra final. Também foi dada atenção aos motivos pelos olhos do governo, pela fala de um ministro de Estado, que alegou que são "um remédio amargo, mas que precisa ser tomado", e pela fala do presidente Temer, por meio de uma nota escrita, em que ele chama as propostas de "modernização da legislação nacional".

O Jornal da Record ignorou os motivos da greve durante sua cobertura. Não fez referência a qualquer um dos pontos criticados pelos sindicalistas, nem se preocupou em contextualizar o que gerou o dia de paralisações. Houve apenas uma referência às reformas trabalhista e da Previdência, mas pela boca dos integrantes do governo, que as defenderam alegando ser "pré-condições para a retomada do crescimento e do emprego". O telejornal, assim, considerou que o público estaria suficientemente informado sobre as causas dos protestos, ou então que não lhe cabia o papel de explicar os motivos das manifestações, apenas mostrar o quanto foram inconvenientes e ilegais.

Os motivos da greve foram abordados pelo grupo Jornalistas Livres durante toda a cobertura, a partir da fala de sindicalistas, seja em entrevistas ou em palavras de ordem entoadas ao longo das manifestações. Mas partiam sempre da mesma premissa, de ser uma tentativa de cassar direitos conquistados pelos trabalhadores. As referências eram genéricas, falando do fim do direito à aposentadoria e de direitos básicos do trabalhador, afirmação fundamentada na ideia de que a relação entre empregado e empregador é de exploração, que precisa ser mediada pelos sindicatos para não se tornar abusiva. Discurso forjado a partir da ideia de Marx, da luta de classes e da alienação do trabalho no capitalismo.

O Coletivo Nigéria e o Marco Zero Conteúdo não fizeram referências claras aos motivos do protesto. A única referência, no caso do Nigéria, surgiu na fala de uma entrevistada, que argumentou ser contrária à retirada do direito à Previdência. Já o Coletivo Catarse apresentou alguns elementos que motivaram as manifestações, tanto a partir da fala dos entrevistados, como ao mos- 
Transtornos e tumulto, ou uma grande festa da democracia? Contrastes da cobertura jornalística...

trar faixas e cartazes que associavam as reformas à volta do trabalho escravo, mas sem detalhar nada nem fazer qualquer contraponto.

\section{5) Referências usadas para explicitar a opinião pública sobre o protesto}

A fala de pessoas comuns, sem identificação, foi a principal forma de expressar a opinião pública contra os protestos pelo Jornal Nacional, o que se deu sem necessariamente haver uma crítica direta às motivações das manifestações, mas sim à sua tática de interromper a circulação do transporte público e bloquear vias públicas. As falas foram distribuídas ao longo das matérias num tom similar, trazendo à tona a vontade daquela pessoa de ir para o trabalho, ou de ir ao consumo, e a impossibilidade criada pelos manifestantes. Há uma única fala de pessoa comum favorável aos protestos, identificada como professora, que diz que é importante não se calar. Outras vozes favoráveis aos protestos eram sempre de manifestantes ou de sindicalistas, o que os afasta dos interesses do público, aproximando-os dos interesses dos sindicatos.

O Jornal da Record também usou como principal estratégia o uso de falas de pessoas comuns não para criticar diretamente as manifestações, mas para mostrar o quanto este tipo de protesto é ilegítimo por atrapalhar o dia a dia das pessoas, causando prejuízos. Mas foi além, ao induzir a ideia de que os protestos geraram medo e perigo para a população. Tal representação do dia de protestos, como perigoso e violento, se deu pelo uso de imagens dos confrontos entre a polícia e os manifestantes (ainda que se restringissem a cenas em que policiais apareciam espancando militantes), bem como pela inclusão de um trecho de áudio em que uma mulher não identificada, que filmava à distância um grupo de manifestantes quebrando telefones públicos em uma praça pública, dizia "Ai, tou com medo". A fala deu verossimilhança ao estado de tensão vivido por quem não queria participar da paralisação, atribuindo aos manifestantes a culpa pela sensação de violência.

Voltado especificamente para comunicar pelas redes sociais, o Jornalistas Livres costuma se apropriar de hashtags para expor sua opinião e difundir causas. No dia da paralisação, em cada publicação, o grupo inscrevia algumas hashtags, entre elas \#ForaTemer, \#BrasilemGreve, \#GreveGeral e \#TôdeGreve. O uso dessas marcas evidencia a tomada de posição do media sem deixar dúvidas de que lado ele está.

Já o Coletivo Nigéria não inseriu qualquer elemento que pudesse evidenciar a opinião pública. Seu trabalho foi tanto dar voz às lideranças dos movimentos populares que protagonizavam o protesto, como ser testemunha das violências cometidas contra os manifestantes. A tal ponto que a cobertura se esforçou para mostrar um segurança da empresa onde acontecia o protesto com um revólver, flagrando o momento em que ele fez um disparo para o alto e passou a ameaçar diretamente os manifestantes. O coletivo também serviu como testemunha no momento em que outros seguranças, usando capacetes para dificultar a identificação, chegaram com um cachorro e o utilizaram para mais uma vez ameaçar os ativistas que estavam ali protestando. Tal função de testemunho é recorrente em práticas de vídeo ativismo (Fauzanafi \& Halaman, 2015; Sousa \& Cervi, 2017) e também é usada para influenciar a opinião pública, ao colocar em clara posição de desigualdade a opressão dos detentores do poder, de um lado, contra militantes desarmados que lutam por causas justas, de outro. 
Já o Marco Zero Conteúdo e o Coletivo Catarse, apesar de não apresentarem referências diretas em relação ao que poderia pensar a população sobre a greve, conseguiram representar uma visão positiva ao expor a forte adesão popular ao protesto e a alegria dos participantes.

\section{Discussão e considerações finais}

A ausência de neutralidade das coberturas tanto do mainstream como dos meios alternativos já era esperada, a partir do que se convencionou no paradigma do protesto. Contudo, as estratégias empregadas sobretudo pelos meios tradicionais surpreenderam, ao priorizar a voz de pessoas comuns, e não fontes oficiais, como costuma acontecer nessas situações. Assim, não bastou mostrar com imagens o caos causado pela interrupção do trânsito e pelos confrontos entre manifestantes e policiais. Apelou-se à fala de cidadãos, trabalhadores, que de algum modo sofreram consequências negativas por causa dos protestos.

Este seria o comportamento esperado normalmente dos meios alternativos, já que o estímulo à participação cidadã é uma das características apontadas pelos estudos da área (Harcup, 2003, 2015). Contudo, como já mostraram Atton e Wickenden (2005), grupos alternativos acabam por criar uma contra-elite de fontes, ligadas a movimentos sociais e sindicatos, ou priorizam falas dos seus próprios jornalistas como testemunhas legítimos dos acontecimentos.

O contexto em que se insere a cobertura influencia a tomada de decisões editoriais de todos os atores analisados. No caso do Jornal Nacional, por exemplo, nitidamente há uma tentativa de reduzir o risco de o telejornal ser acusado de manipulador, ao inserir a fala de sindicalistas e de pessoas comuns para comentar o dia de protestos, ao expor os motivos que levaram às manifestações e ao tentar diferenciar manifestantes e sindicalistas dos vândalos mascarados, ainda que ambos os grupos fizessem parte das mesmas manifestações. Essa tentativa de se eximir de críticas mais contundentes ficou ainda mais evidenciada no final de edição sobre os protestos, quando apresentou um resumo da cobertura feita pela emissora, em todo o país, numa autorreferenciação que também tinha a intenção de endossá-la como mediadora legítima da sociedade e fonte segura de informação e de serviço. Preocupação que claramente a TV Record não teve em seu telejornal. Pelo contrário, a emissora acabou por fazer uma cobertura estritamente condenatória das manifestações, se encaixando fielmente às prerrogativas do paradigma do protesto, ao buscar deslegitimar as ações tanto pela tática e violência dos atos, como ao não expor os motivos e pela pressão da opinião pública, bem em acordo com as orientações do grupo religioso que detém sua propriedade e que apoia o governo Temer (a TV Globo passou a se opor a Temer, apesar de ser favorável às reformas).

No caso dos alternativos, o posicionamento positivo dos grupos não os afastou por completo do paradigma do protesto, já que eles priorizaram mostrar as manifestações como festa, não se aprofundaram na exposição dos motivos e acabaram por enfatizar situações de conflito, ainda que para denunciar a violência policial. Um elemento diferencial é o fato de realizarem a cobertura em meio aos manifestantes, o que possibilita mostrar suas faces e seu comportamento, o que os humaniza. Fator extremamente relevante na construção da empatia para com a audiência.

Mas, e afinal, o que foi esse dia de manifestação? O caos ou uma festa cidadã? Mais do que uma resposta, a análise nos leva a uma reflexão sobre o papel do jornalismo na construção de 
uma sociedade mais plural e aberta ao debate. Afinal, é positivo que não apenas a versão tradicional, que marginaliza os protestos, seja evidenciada no espaço mediático. Contudo, a falta de abertura dos dois lados a expor as divergências parece não contribuir para estimular o debate público. Pelo contrário, reforça as bolhas sociais cada vez mais intransponíveis no ambiente virtual. Cultiva-se, assim, um ambiente antagônico, de divergências insanáveis, e não um espaço agônico, como propôs Mouffe (2013), em que as diferenças são expostas e debatidas, sem consensos, mas respeitadas.

\section{Referências Bibliográficas}

Atton, C. (2011). Alternative journalism. In J. D. H. Downing (ed.), Encyclopedia of social movement media. Thousand Oaks, London, New Delhi: Sage.

Atton, C. \& Hamilton, J. F. (2008). Alternative journalism (1st ed.). London: S. Publications Ed.

Atton, C. \& Wickenden, E. (2005). Sourcing routines and representations in alternative journalism: a case study approach. Journalism Studies, 6(3), 347-359. doi: http://dx.doi.org/10.108 0/14616700500132008

Boykoff, M. T. \& Boykoff, J. M. (2004). Balance as bias: global warming and the us prestige press. Global Environmental Change (14), 125-136.

Boyle, M. P.; McLeod, D. M. \& Armstrong, C. L. (2012). Adherence to the protest paradigm: the influence of protest goals and tactics on news coverage in US and international newspapers. The International Journal of Press/Politics, 17(2), 127-144.

Cammaerts, B. (2012). Protest logics and the mediation opportunity structure. European Journal of Communication, 27(2), 117-134. doi: http://dx.doi.org/10.1177/0267323112441007

Carpentier, N. \& Trioen, M. (2010). The particularity of objectivity: a post-structuralist and psychoanalytical reading of the gap between objectivity-as-a-value and objectivity-as-a-practice in the 2003 Iraqi War coverage. Journalism, 11(3), 311-328. doi: http://dx.doi.org/10.1177/1 464884909360922

Chan, J. M. \& Lee, C.-C. (1984). The journalistic paradigm on civil protests: a case study of Hong Kong. The news media in national and international conflict, 183-202.

Charaudeau, P. (2006). Discurso das mídias (Trans. A. M. S.Corrêa). São Paulo: Contexto.

Dardis, F. E. (2006). Marginalization devices in U.S. Press coverage of Iraq war protest: A content analysis. Mass Communication \& Society, 9(2), 117-135. doi: http://dx.doi.org/10.1207/s153 27825mcs0902_1

Deuze, M. (2005). What is Journalism? Professional identity and ideology of journalists reconsidered. Journalism, 6(4), 442-464. doi: http://dx.doi.org/10.1177/1464884905056815

Entman, R. M. (2004). Projections of power: framing news, public opinion, and U.S. foreign policy. University of Chicago Press.

Fauzanafi, M. Z. \& Halaman, K. (2015). 'We don't work with video, we work with People': reflections on participatory video activism in Indonesia. The Fibreculture Journal, (26), 314320 . 
Forde, S. (2011). Challenging the news: the journalism of alternative and community media. Palgrave Macmillan.

Gitlin, T. (1980). The whole world is watching. Mass media in the making \& unmaking of the new left. Berkeley, Los Angeles, London: University of California Press.

Hall, S. (1978). The social production of news. In S. Hall (ed.), Policing the crisis: mugging the state, and law and order. London: Macmillan.

Halliday, M. A. K. (1985). An introduction to functional grammar. London: Edward Arnold Press.

Harcup, T. (2003). The unspoken - said': the journalism of alternative media. Journalism, 4(3), 356-376. doi: http://dx.doi.org/10.1177/14648849030043006

Harcup, T. (2015). Listening to the voiceless: the practices and ethics of alternative journalism. In C. Atton (ed.), The Routledge companion to alternative and community media. London: Routledge.

Harlow, S. (2017). Recognizing the importance of alternative media. Journalism Studies, 1-19. doi: http://dx.doi.org/10.1080/1461670X.2017.1364139

Harlow, S.; Salaverría, R.; Kilgo, D. K. \& García-Perdomo, V. (2017). Protest paradigm in multimedia: social media sharing of coverage about the crime of Ayotzinapa, Mexico. Journal of Communication, 67(3), 328-349. doi: http://dx.doi.org/10.1111/jcom.12296

Hopke, J. E. (2012). Water gives life: framing an environmental justice movement in the mainstream and alternative salvadoran press. Environmental Communication-a Journal of Nature and Culture, 6(3), 365-382. doi: http://dx.doi.org/10.1080/17524032.2012.695742

Kress, G. \& van Leeuwen, T. (2001). Multimodal discourse: Bloomsbury Academic.

Lee, F. L. F. (2014). Triggering the protest paradigm: examinins factors affecting news coverage of protests. International Journal of Communication, 8, 2725-2746.

Machin, D. \& Mayr, A. (2012). How to do critical discourse analysis - a multimodal introduction. Los Angeles, London, New Delhi: Sage.

McLeod, D. M. \& Detenber, B. H. (1999). Framing effects of television news coverage of social protest. Journal of communication, 49(3), 3-23.

Moretzsohn, S. (2002). "Profissionalismo" e "objetividade": o jornalismo na contramão da política. In L. G. Motta (ed.), Imprensa e poder (pp. 199-216). Brasília: Editora Universidade de Brasília.

Mouffe, C. (2013). Agonistics - thinking the world politically. London, New York: Verso.

O’Halloran, K. \& Smith, B. (2011). Multimodal studies. In K. O'Halloran \& B. Smith (ed.), Multimodal studies - exploring issues and domains. London, New York: Routledge.

Reul, R.; Paulussen, S.; Raeijmaekers, D.; van der Steen, L. \& Maeseele, P. (2016). Professional journalistic routines and the protest paradigm: the Big Potato Swap in traditional and alternative media. Journalism, 1-18. 
Rodriguez, C. (2001). Fissures in the mediascape: an international study of citizens' media. Hampton Press.

Rodriguez, C.; Ferron, B. \& Shamas, K. (2014). Four challenges in the field of alternative, radical and citizens' media research. Media Culture \& Society, 36(2), 150-166.

Schudson, M. (2001). The objectivity norm in American journalism Journalism, 2 (2), 149-170. doi: http://dx.doi.org/10.1177/146488490100200201

Shahin, S.; Zheng, P.; Sturm, H. A. \& Fadnis, D. (2016). Protesting the paradigm: a comparative study of news coverage of protests in Brazil, China, and India. The International Journal of Press/Politics, 21(2), 143-164. doi: http://dx.doi.org/10.1177/19401616631114

Sousa, A. L. N. \& Cervi, L. (2017). Video activism in the Brazilian protests: genres, narratives and political participation. Northern Lights, 15, 69-88. doi: http://dx.doi.org/10.1386/nl.15.69_1

Sponholz, L. (2003). Objetividade em jornalismo: uma perspectiva da teoria do conhecimento. Famecos, (21), 110-120.

Tuchman, G. (1972). Objectivity as strategic ritual: an examination of newsmen's notions of objectivity. American Journal of Sociology, 77 (4), 660-679.

van Dijk, T. A. (2015). Racism and the press: Taylor \& Francis.

Weaver, D. A. \& Scacco, J. M. (2013). Revisiting the protest paradigm: the tea party as filtered through prime-time cable news. The International Journal of Press/Politics, 18(1), 61-84. 